\title{
Technologies and technical devices for annual regulated flooding of a productive strata
}

\author{
Kadyrov Ramzis Rakhimovich \\ Ufa State Petroleum Technological University, \\ Branch of the University in the City of Oktyabrsky, Russian \\ Federation \\ E-mail: mark1212@mail.ru
}

\author{
Kuleshova Lubov Sergeevna \\ Ufa State Petroleum Technological University, \\ Branch of the University in the City of Oktyabrsky, Russian \\ Federation \\ E-mail: mark1212@mail.ru
}

\author{
Fattakhov Irik Galikhanovich \\ Ufa State Petroleum Technological University, \\ Branch of the University in the City of Oktyabrsky, Russian Federation \\ E-mail: mark1212@mail.ru
}

\begin{abstract}
Different systems of stratal flooding by mineral or fresh water into oil bearing formation are used today to enhance reservoir recovery. At low temperatures, 25 degrees below zero and lower, there is a great possibility of freezing of the well head equipment due to cyclic flooding or separate horizontal flooding, lessening injection capacity of the well, emergency stops in flooding, due to water pipe breakage or power cutting off. Besides the wells, crossover bends from water injection wells to the pipe header, and stagnation zones of the embedded in grooves pipes can freeze. According to expert estimation of PJSC "Tatneft" specialists, the amount of frozen injection stations is more than 500 wells per year. Due to the urgency of the issue technological measures have been developed to prevent oil-field equipment freezing.
\end{abstract}

Keywords - freezing prevention; oil-field equipment; annual regulated flooding.

\section{INTRODUCTION}

Nowadays, PJSC "Tatneft" uses reservoir pressure maintenance system (RPMS) with complex structure of reservoir engineering, including great amount of water injection wells (about 10 thousands), with injection capacity $100 \mathrm{~m}^{3} /$ day, working from cluster pump stations (CPS), equipped with centrifugal pumps. The distance between CPS and water injection wells is about $2 \mathrm{~km}$, and the distance from treating facilities to CPS varies from several up to thirty kilometers. Besides for enhanced oil recovery system pressure maintenance upgrades are used. Non-stationary flooding is the most effective method. It is especially difficult to use during winter periods especially in emergency downtime, caused by injection well head freezing. According to expert estimation, up to nine oil-gas producing installations of PJSC "Tatneft," up to 800 waterinjection wells are idle during winter because of freezing, as well as many parts of water-injection wells are switched off to avoid their heads freezing. That is why taking preventive measures from injection well heads and water pipes freezing is acute.
We suggest a method of preventing injection well heads freezing by non-stationary flooding and its perspective annual utilization on the example of oil-deposits of PJSC "Tatneft", PJSC JSOC "Bashneft" and PJSC OC "Rosneft", and operation clustering for water shut-off.

To analyze stability of field development with nonstationary flooding seasonality coefficient $\varphi$ [1] was suggested which is determined by formula:

$$
\varphi=\frac{\sum_{i=1}^{n} X_{i} / n}{\sqrt{\frac{1}{n-1} \sum_{i=1}^{n}\left(X_{i}-\bar{X}\right)^{2}}}=\frac{\bar{X}}{s},
$$

Where $\mathrm{n}$ is a sample amount; $\mathrm{X}$ is a variable; $\overline{\mathrm{X}}$ is observed mean, $\mathrm{s}$ is standard deviation.

All analyzed data should be in a standardized view. A threshold value of the seasonality coefficient is number 10 , derived from observational error method, inaccuracy mean value (based on the analyzed set number parameters) in oil industry (also it evidences minimal process variability) not more than $20 \%$. As it follows from the analysis, the least values correspond to injected water volume $\mathrm{Q}_{\mathrm{inj}}$, providing drainage injection $\mathrm{Q}_{\mathrm{inj}} / \mathrm{Q}_{\mathrm{wpl}}$ and the water cut of the product B. Average value showed that the rest of the parameters have value more than 10 , though $\mathrm{Q}_{\text {inj }}$ and $\mathrm{B}$ nearly 3-8 times less [2]. This fact evidences necessity to control seasonal changes and proves irregularity in non-stationary injection system at winter period of operation.

Every year due to irregularity in cyclic flooding, forced stoppage of water-injection wells due to emergency or other reasons of idle hours the oil companies PJSC "Tatneft", PJSC JSOC "Bashneft" and PJSC OC "Rosneft" produce about 34 thousand tons of oil less, for four years it is more than 137 thousands of oil tons less. Besides well head freezing water injection wells are intentionally stopped, in order to function in summer otherwise if they freeze they will thaw only in the middle of June. 
Nowadays, liquid thermal insulation of pipes, containers and well heads is used as well as traditional heat insulating materials. But even this modern way of insulating in low temperatures, water injection stoppage, lowering of injection capacity prevents well heads freezing from 1 to 3 days and nights. To provide operation of water injection well for longer period it is necessary to use additional sources of heat such as pipage of relic warm earth, application of pipe tracers and others. [3].

In order to heat water injection wells heads with natural earth warmth in winter convection heat interchangers have been designed.

In central parts of Russia at the depth of 1, $6 \mathrm{~m}$ there is a zone of stable positive temperatures. With the depth temperature increases gradually so the optimal depth for placing a convection heat interchanger is 2,5-3 m. Picture 1 shows the model of a convection heat interchanger for heads heating, with a radiator in the heated zone. Its advantage is large contact surface with earth with simple production $[4,5]$.

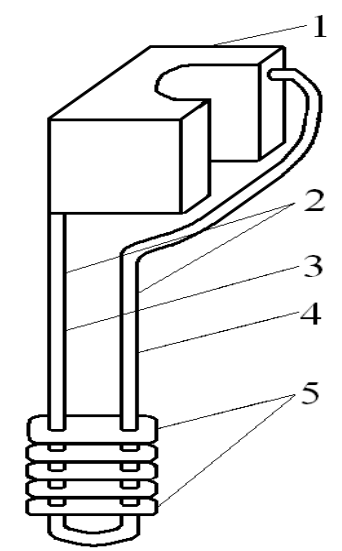

Fig. 1. Convective heat interchanger: 1 - head heating case; 2 - rubber hose; 3 - descending line; 4 - rising line; 5 - radiator

The designed construction of the convection heat interchanger for water injection wells head heating was tested in January-February in the laboratory of TatNIPIneft R\&D Institute. For this, two shotholes with the diameter 400 $\mathrm{mm}$ and depth of 3 meters were made in the open ground.

Two convectional heat interchangers were placed into them. At the surface the upper part of the heat interchanger was covered with a cap to prevent heat loss.

The tests were conducted in January - February at temperatures from 9 degrees below zero to 22 degrees below zero. The temperature inside the cap and outside the cap was fixed daily. The observation was done through thick organic glass. The tests showed that during outer temperature changes the temperature inside the heating case was never lower $0^{\circ} \mathrm{C}$. Dynamics of temperature changes in the interval from 0 to $2^{\circ} \mathrm{C}$ above zero at the surface of the heater case proves reliability of the designed device and applicability of the earth warmth for well head heating [6, 7]. Convectional heat interchangers for transmitting earth warmth to injection tree KT-SH-114 and KT-S-48 were designed basing on these tests [8].

Also, the way to prevent injection well heads from freezing with the use of saving and using earth warmth has been developed (fig. 2) [9]; as well as the manual for the prevention of injection well heads freezing.

This method provides stable functioning of the injection well head tree during seasonal temperature lowering below zero degrees. In case of emergency or any other stoppage and temperature lowering the process of convectional heat transfer takes place from the earth to the injection tree. Successful testing of the conventional heat interchangers has been done at the wells [10].

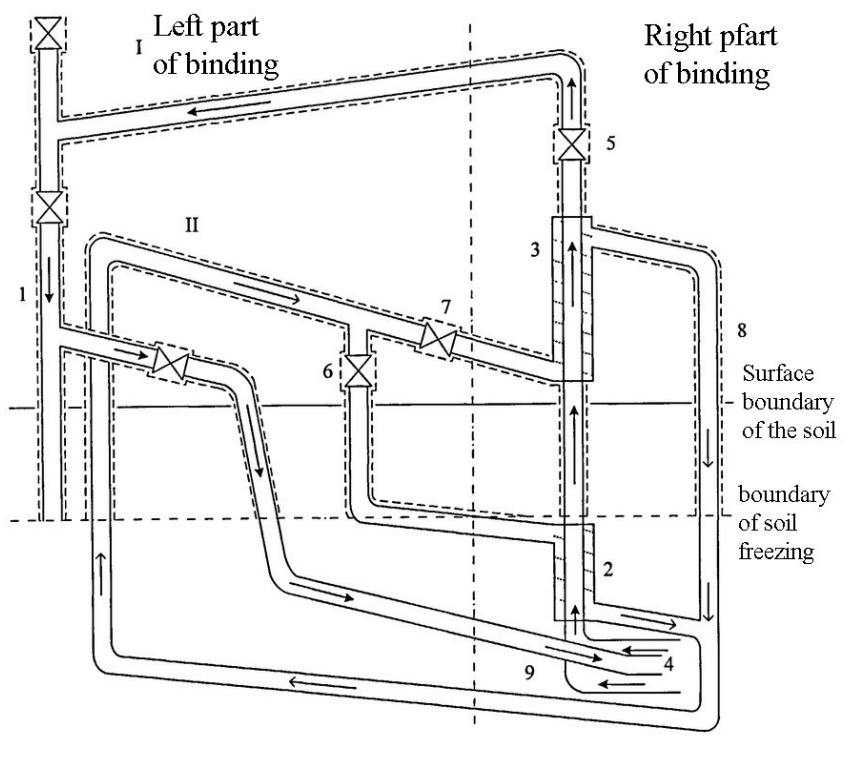

$\longrightarrow$ water $\longrightarrow$ freon

Fig. 2. Two circuit convectional head heat interchanger: I - Upper contour of binding; II - lower contour of binding; 1 - injection head tree; 2 - first heat interchanger; 3 - second heat interchanger; 4 - water pipe; 5 - upper master valve; 6,7 - valves for connecting and disconnecting the first and the second heat interchanger; 8,9 - pipe

In case of exhausting of the warmth of the surrounding area another way of water injection heads heating was suggested - with the help of the heating trace. Heat transfer with periodic electrical heating of the circulating water by electrical heater was developed and tested. It was conditioned by the fact that at $4{ }^{\circ} \mathrm{C}$ above zero water has maximum density and convection is impossible. The scheme of earth heat utilization with periodic utilization of electrical heaters is shown in picture 3. After reaching the temperature, at which water circulation by convection is possible (from $+5{ }^{\circ} \mathrm{C}$ ), heating elements are automatically switched off by a controller.

This method was tested at 9 wells of NGDU "Aznakayevskneft", "Yamashneft, PJSC "Tatneft", each of them had heating strips with further insulating. The test results showed that heaters ENGL are not suitable for long term heating, and the efficiency of heaters 31 FSR-2ST is 80 $\%$ (for enhancing their productivity up to $100 \%$ heat 
controllers and independent systems of protection from overload current should be used).

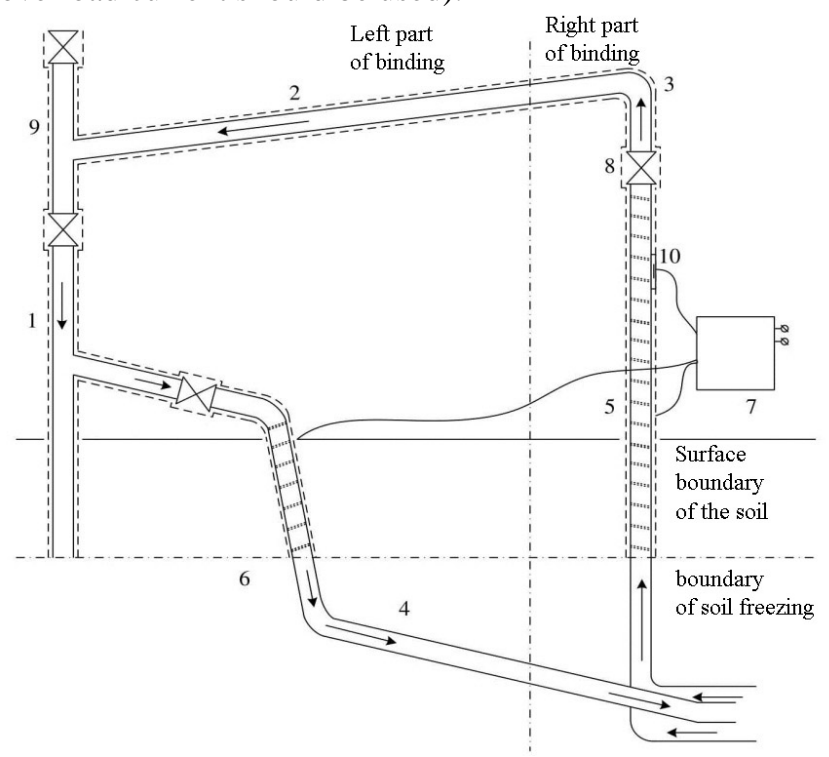

Fig. 3. Assembling scheme of the heating strip on the injection tree and necessary equipment: 1 -injection tree; 2 - left upper arm of the binding contour; 3 - right arm of the binding contour; 4 - left lower arm of the binding contour; 5,6 - heating strip; 7 - control unit; 8 - central valve; 9 - insulating material «ROCKWOOL»; 10 - temperature sensor

In order to improve the existing flooding system a new technological scheme has been suggested. This scheme is based on the perspectives of annual cyclic water pumping into water injection well (picture 4), involving connecting to low-pressure flow passages of electrical submersible centrifugal pump, in a shot hole close to water injection well and water passage [6]. The pumping fluid is fed to the pump suction of the electric centrifugal pump (ECP) through the low pressure flow passage, and the outlet side is connected with injection wells.

To avoid corrosion wear and shot hole case destruction because of fluid freezing during idle time in cold seasons, resulting in ECP destruction, it has been suggested to install an intermediate leak-proof column. The space between it and a casing column should be filled with rust-preventive non-freezing fluid (oil with non-freezing additive), which will avoid metal corrosion.

This technology allows water injecting into one or several wells in the pressure range from 8,5 to $19,0 \mathrm{MPa}$ with the discharge from 20 to $1000 \mathrm{~m}^{3} /$ day, in other words, applying ECP annually as injection pump tree with possibility to group wells according to their intake capacity and injection pressure.

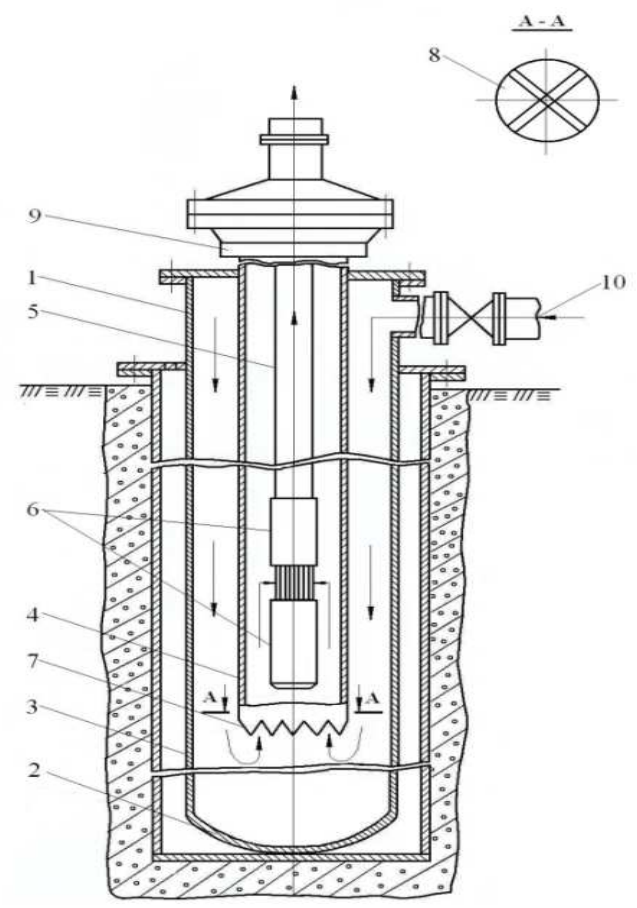

Fig. 4. Electric centrifugal pump installation in a shot hole with an intermediate column (case): 1 -intermediate leak tight column; 2 - elliptic bottom of the leak-tight column; 3 - casing column; 4 - inner sectional pipe; 5 - lifting pipe; 6 - ECP; 7 - but-end teeth of the inner side of the section pipe; 8 - cross separation of the inner sectional pipe with the inclined blades; 9 - fillets; 10 - leading pipe line

As formation - pressure maintenance system has many recommendations and conditions, one issue remains important - how to prevent intake tunnels from freezing in winter time. This issue is especially acute in emergency well stops or during utilization of cyclic flooding system in cold season. It is suggested to summarize temperature distribution in culverts and over land water passages with the use of designed software "Astan" and "Esten" [11].

Software "Astan" is a tool for calculating water final temperature of culverts. For calculation ground thermal conductivity is taken as equal $0,289 \mathrm{kkal} /\left(\right.$ hour $\left.\cdot \mathrm{m}^{\circ} \mathrm{C}\right)$, and earth heat emission is $6,948 \mathrm{kkal} /\left(\right.$ hour $\left.\cdot \mathrm{m}^{2} \cdot{ }^{\circ} \mathrm{C}\right)$. Upon data feeding completion pipe heat emission coefficient at a given moment of water passage utilization can take values in the range $0,003-21 \mathrm{kkal} / \mathrm{m}^{2}$.hour degrees (the last is for extreme weather conditions, for example, strong wind).

On the completion of entering necessary variants number we receive information for every case (it corresponds to the table line) about possible water freezing and final water temperature. In particular it shows the starting point of water freezing; freezing imaginary period, for the case when the water passage is longer; or complete freezing coordinate.

According to the tests, initial water temperature change varies from 10 to $70{ }^{\circ} \mathrm{C}$, air temperature lowered from minus 5 to minus $25^{\circ} \mathrm{C}$. Water freezing temperature is taken as constant and equal $0{ }^{\circ} \mathrm{C}$, that is, water is taken as fresh as mineral waters have lower degree of freezing [12]. Tables of final water temperatures have been received for feeding 
water passage for all combinations with denoting (if necessary) coordinates of icing beginning (in meters from the pipeline beginning) or expected water freeze (coordination derivation of complete freezing, measured in meters).

The received data show that additional heating of water pumped into water passages is necessary (especially for surface water passages) [13]. It is found that for culverts the carrier temperature $20{ }^{\circ} \mathrm{C}$ is cost effective. Also, it is recommended to use outer insulation for water flows, in particular insulating paints, that will decrease heat loss and is not difficult to apply and maintenance. It has been found that even in extreme conditions (such as strong winds the heat loss is $21 \mathrm{Wt} \cdot \mathrm{m}^{2} \cdot{ }^{\circ} \mathrm{C}$ ) complete freezing of the water passage will happen at the length of more than $3,5 \mathrm{~km}$. For heating water passage it is suggested to use heating capacity of the accompanying gases (corresponding calculations have been done with assumptions) for flare that will increase water pumping efficiency and decrease taxation for gas flaring into atmosphere. In particular, there are such possibilities at NGDU "Yamashneft" and others.

\section{CONCLUSION}

We can make the following conclusions:

1. It is found that the main enhancing factor of oil layers development by water pumping is providing possibility of annual regulated flooding (by using earth heat and abnormal properties of water density) and limitation of the associated water inflow into oil producing wells.

2. A new method of oil development enhancing is suggested. It is based on statistical analysis and combines complex use of monitoring computer technologies of cyclic flooding efficiency with providing annual regulated water pumping into productive layers and water shut-off works in wells.

3. Complex of technologies and technical devices is designed reservoir pressure maintenance system functioning by fresh and mineral water flooding in negative temperatures. This complex provides annual cyclic functioning.

4. Methodological grounds are developed, as well as functioning principles; devices for accumulating and transporting earth heat are designed for injection well head heating.

5. The technological scheme of reservoir pressure maintenance by an electric centrifugal pump in the shot hole, placed close to water injection well, below soil freezing point and connected at the feeding end of the electric centrifugal low pressure water conducting passage of the pump, which prevents injection well head freezing, reducing energetic and material costs has been designed at NGDU "Yamashneft" PJSC "Tatneft".

6. The mobile complex for electro-heating of well head water injection equipment and adjusting parts of the culverts has been designed, tested and produced basing on the new effective, small-size transformer, providing reduction of maintenance costs in comparison with traditional application of heating by vapor-movable device.

7. Basing on the comparative operation efficiency testing of protection from freezing of the well head equipment, water injection wells and adjusted ground surface pipe-lines, the efficiency of self-regulating electro-heating stripes type 31 FSR-2CT and insulating paints has been proved.

\section{References}

[1] H. Pei, Z. Shu, G. Zhang, J. Ge, P. Jiang, Y. Qin, X. Cao, Experimental study of nanoparticle and surfactant stabilized emulsion flooding to enhance heavy oil recovery, Journal of Petroleum Science and Engineering, Vol. 163, № 4, pp. 476-483, 2018.

[2] T. Lu, Z. Li, Y. Zhou, C. Zhang, Enhanced Oil Recovery of LowPermeability Cores by SiO2 Nanofluid, Energy and Fuels, Vol. 31,№ 5, pp. 5612-5621, 2017.

[3] T. Lu, Z. Li, Y. Zhou, Flow behavior and displacement mechanisms of nanoparticle stabilized foam flooding for enhanced heavy oil recovery, Energies, Vol. 10, № 4, 560, 2017.

[4] Jon Limberger, Thijs Boxem and etc, Geothermal energy in deep aquifers: A global assessment of the resource base for direct heat utilization, Renewable and Sustainable Energy Reviews, Vol. 82, part 1, pp.961-975, 2018.

[5] Hourfar Farzad, Moshiri Behzad, Salahshoor Karim, Real-time management of the waterflooding process using proxy reservoir modeling and data fusion theory, Computers \& chemical engineering, Vol. 106, pp. 339-354, 2017.

[6] V.V. Sergeev, N.G. Belenkova, Yu.V. Zeigman, and V.Sh. Mukhametshin, "Physical properties of emulsion systems with $\mathrm{SiO}_{2}$ nanoparticles," Nanotechnologies in Construction, vol. 9, no. 6, 2017, pp. 37-64. DOI: 10.15828/2075-8545-2017-9-6-37-64.

[7] G.R. Izmailova, L.A. Kovaleva, N.M. Nasyrov, Acoustic wave energy absorption and distributed heat sources upon an acoustic impact on media, High temperature, Vol. 54, № 1, pp. 56-61, 2016.

[8] V.N. Polyakov, Yu.V. Zeigman, Yu.A. Kotenev, V.V. Mukhametshin, Sh.Kh. Sultanov, and A.P. Chizhov, "System solution for technological problems of well construction completion," Nanotechnologies in Construction, vol. 10, no. 1, pp. 72-87, 2018. DOI: 10.15828/2075-8545-2018-10-1-72-87.

[9] V.V. Mukhametshin, "Efficiency estimation of nanotechnologies applied in constructed wells to accelerate field development," Nanotechnologies in Construction, vol. 10, no. 1, pp. 113-131, 2018. DOI: 10.15828/2075-8545-2018-10-1-113-131.

[10] V.V. Mukhametshin and R.R. Kadyrov, "Influence of nanoadditives on mechanical and isolating properties of cement-based compositions," Nanotechnologies in Construction, vol. 9, no. 6, pp. 18-36, 2017. DOI: 10.15828/2075-8545-2017-9-6-18-36.

[11] O.A. Grezina, "Efficiency evaluation for nanomaterials applied in well bottom zone treatment after completion of well construction," Nanotechnologies in Construction, vol. 9, no. 6, pp. 65-86, 2017. DOI: 10.15828/2075-8545-2017-9-6-65-86.

[12] R.N. Bahtizin, I.G. Fattakhov, R.R. Kadyrov, T.U. Jusifov, S.A. Rabcevich, F.R. Safin, A.S. Galushka, "Importance of modeling application to increase oil recovery ratio," Middle East Journal of Scientific Research, Issue 17(11), pp. 1621-1625, 2013. http://www.idosi.org/mejsr/mejsr17(11)13/22.pdf

[13] M.V. Goryunova, L.S. Kuleshova and A.I. Khakimova, "Application of signal analysis for diagnostics," International Conference on Industrial Engineering, Applications and Manufacturing (ICIEAM) (Saint Petersburg: IEEE), pp. 1-5, $2017 . \quad$ DOI: 10.1109/ICIEAM.2017.8076487. 